\title{
Relation between health literacy, self-care and adherence to treatment with oral anticoagulants in adults: a narrative systematic review
}

\author{
Ana Cristina Cabellos-García ${ }^{1}$, Antonio Martínez-Sabater ${ }^{2}$, Enrique Castro-Sánchez ${ }^{3 *}$ (D, Mari Kangasniemi ${ }^{4}$, \\ Raul Juárez-Vela ${ }^{5}$ and Vicente Gea-Caballero ${ }^{6,7}$
}

\begin{abstract}
Background: Oral anticoagulants $(\mathrm{OAC})$ are widely used in patients with cardiovascular diseases. However, for optimal OAC self-care patients must have skills, among which health literacy $(\mathrm{HL})$ is highlighted. We aimed to describe the relation between $\mathrm{HL}$ and self-care in cardiovascular patients on OAC treatment.

Methods: Electronic searches were carried out in the PubMed, Scopus, Embase, CINAHL, Web of Science, Cochrane Library, SciELO, IME-Biomedicina, CUIDEN Plus and LILACS databases, limited to Spanish and English language and between January 2000-December 2016. Papers reported on adults older than 18 years, taking OAC by themselves for at least three months. PRISMA guidelines were used for paper selection.

Results: We identified 142 articles and finally included 10; almost all of them about warfarin. Our results suggest that in patients taking OAC treatments there is a positive relationship between $\mathrm{HL}$ and the level of knowledge. In addition, a small percentage of participants on the selected papers recognized the side effects and complications associated with OAC treatment. Lower HL level was associated with greater knowledge deficits and less adherence to treatment.

Conclusion: There is a paucity of research evaluating the effect of $\mathrm{HL}$ on diverse aspects of OAC treatments. There is a need to expand the evidence base regarding appropriate $\mathrm{HL}$ screening tools, determinants of adequate knowledge and optimal behaviours related to OAC self-management.
\end{abstract}

Keywords: Health literacy, Oral coagulation therapy, Self-management, Self-care, Adherence, Systematic review

\section{Background}

According to the World Health Organization (WHO), cardiovascular diseases are the leading global cause of death. Among the cardiovascular health problems, atrial fibrillation (AF) is the most frequent arrhythmia $[1,2]$ being associated with high mortality and morbidity and the chief cause of embolic events. Estimates suggest that the prevalence of AF in Europe will increase by $60 \%$ between 2010 and 2040, [3, 4] which may explain the

* Correspondence: e.castro-sanchez@imperial.ac.uk

${ }^{3} \mathrm{NIHR}$ Health Protection Research Unit in Healthcare Associated Infection and Antimicrobial Resistance at Imperial College London, Du Cane Road, W12 0NN, London, UK

Full list of author information is available at the end of the article increased use in recent years of highly effective therapies such as oral anticoagulation (OAC) therapies [5, 6].

$\mathrm{OACs}$ are used to maintain adequate coagulation levels and thus prevent thrombotic episodes. These drugs present particular characteristics (daily dose with great variability, narrow therapeutic range, complex pharmacokinetic and pharmacodynamic profile and possibility of both thrombotic and haemorrhagic complications) that make necessary periodic blood tests and careful clinical control. The International Normalized Ratio (INR) blood test is used to discern the effectiveness and safety of the treatment, with results between 2 and 3 considered adequate. When $60 \%$ of INR measurements in a patient are within such range (denominated Time in Therapeutic Range, TTR), the underlying

(c) The Author(s). 2018 Open Access This article is distributed under the terms of the Creative Commons Attribution 4.0 International License (http://creativecommons.org/licenses/by/4.0/), which permits unrestricted use, distribution, and reproduction in any medium, provided you give appropriate credit to the original author(s) and the source, provide a link to the Creative Commons license, and indicate if changes were made. The Creative Commons Public Domain Dedication waiver (http://creativecommons.org/publicdomain/zero/1.0/) applies to the data made available in this article, unless otherwise stated. 
cardiac problem is considered to be well controlled if the measurement is performed by the direct method (percentage of controls in range) during a valuation period of at least 6 months. If measurements are calculated by the Ronsendaal method, then guidelines recommend TTR $>70 \%[1,5-8]$. Adequate health knowledge and patients' self-care are therefore vital to maintain an optimal treatment concordance due to the complexity of the condition and drug characteristics.

Health literacy (HL) has been identified as a crucial determinant of public and individual health as well as self-care $[9,10]$. Conceptually, HL is dynamic and refers to the knowledge, motivation, and competencies to act, understand, evaluate and apply health information to care-related decisions [11-13]. Currently, different tools are used to measure HL levels encompassing communication skills, information search capability, and previous experience of health care [14-16]. In recent years, the emphasis has been placed on the adaptation of health and social care systems to the HL of the population, to facilitate and optimize human and material resources and improve clinical and health outcomes.

Some preliminary studies exploring the effect of HL on awareness about AF and medication concordance suggest that patients with low HL were less likely to take treatment as recommended, therefore increasing the risk of complications and disease-related mortality [17]. These results match well those reported in other chronic diseases where people with low HL experienced worse health status and outcomes, $[18,19]$ suboptimal management of treatment with direct consequences such as medication errors, [20] higher risk of hospital admission, [21] increased social costs, [22, 23] less use of preventive services and in essence higher mortality. [24-26] The association between low HL and decreased knowledge regarding factors of disease prevention, medicines use, the importance of dose adjustment and adherence to treatment has also been described [27-29].

The aim of this systematic review was to describe the influence of HL levels in the self-care of cardiovascular pathologies managed with OAC treatment. The research questions were:

1. In patients taking OAC treatments, what is the relationship between HL levels and selfmanagement/self-care, adverse effects and complications?

2. What instruments have been used to determine levels of health literacy in patients taking OAC treatments?

3. What has been the impact of health interventions tailored to the level of $\mathrm{HL}$ in the adherence to OAC treatments, as evidenced by changes in INR results?

\section{Methods}

We conducted a systematic review following PRISMA guidelines [30]. In the first stage, we built a search strategy with the following PICO approach (Table 1).

\section{Literature searches}

We searched the electronic databases PubMed, Scopus, Embase, CINAHL, Web of Science, Cochrane Library (all these in English), and SciELO, IME-Biomedicina, CUIDEN Plus and LILACS (in Spanish). Search terms were identified used the DeCS, MeSH and Tesauro PsycINFO tools, combining the terms 'adult patients,' 'oral coagulation therapy', 'health literacy,' 'self-care,' 'self-management' and 'medication adherence', and appropriate synonyms in English and Spanish. We combined the search terms with Boolean operators "OR" and "AND" (Fig. 1).

We included papers which focused on i) patients older than 18 years, ii) on oral coagulation therapy for at least three months, and where iii) patients were taking medication by themselves. Additionally, papers had to report on studies conducted in iv) primary healthcare settings using v) qualitative or quantitative methods, including economic studies. We excluded papers that focused on i) patients with neurocognitive impairments, dementia or mental health disorders and ii) inpatients or patients admitted to hospitals or similar settings.

As limits to the search, the papers had to be published in Spanish or English between January 2000 and December 2016 in a peer-reviewed scientific journal. In addition, an abstract had to be available.

\section{Data evaluation}

After completion of paper selection, we evaluated the quality of manuscripts with ICROMS tool (Integrated Quality Criteria for the Review of Multiple Study designs) for assessing Risk of Bias [31], which has been used previously in various articles $[32,33]$. Data were selected and analysed by two authors working independently. In case of disagreement, a third author was consulted.

\section{Data analysis}

As a first stage of analysis, the selected papers were read several times to get a clear picture and understanding. After that, information within the papers was tabulated in a standardised form according to authorship, year, country, aims, methodology, and population and sample

Table 1 Overall structure of the systematic review

\begin{tabular}{ll}
\hline $\mathrm{P}$ (patients) & Adults patients on oral coagulation therapy \\
\hline I (intervention) & Measures to assess and improve health literacy \\
$\mathrm{C}$ (comparison) & $\begin{array}{l}\text { Inappropriate due to there are no concepts } \\
\text { to compare } \\
\text { O (outcome) }\end{array}$ \\
\hline
\end{tabular}




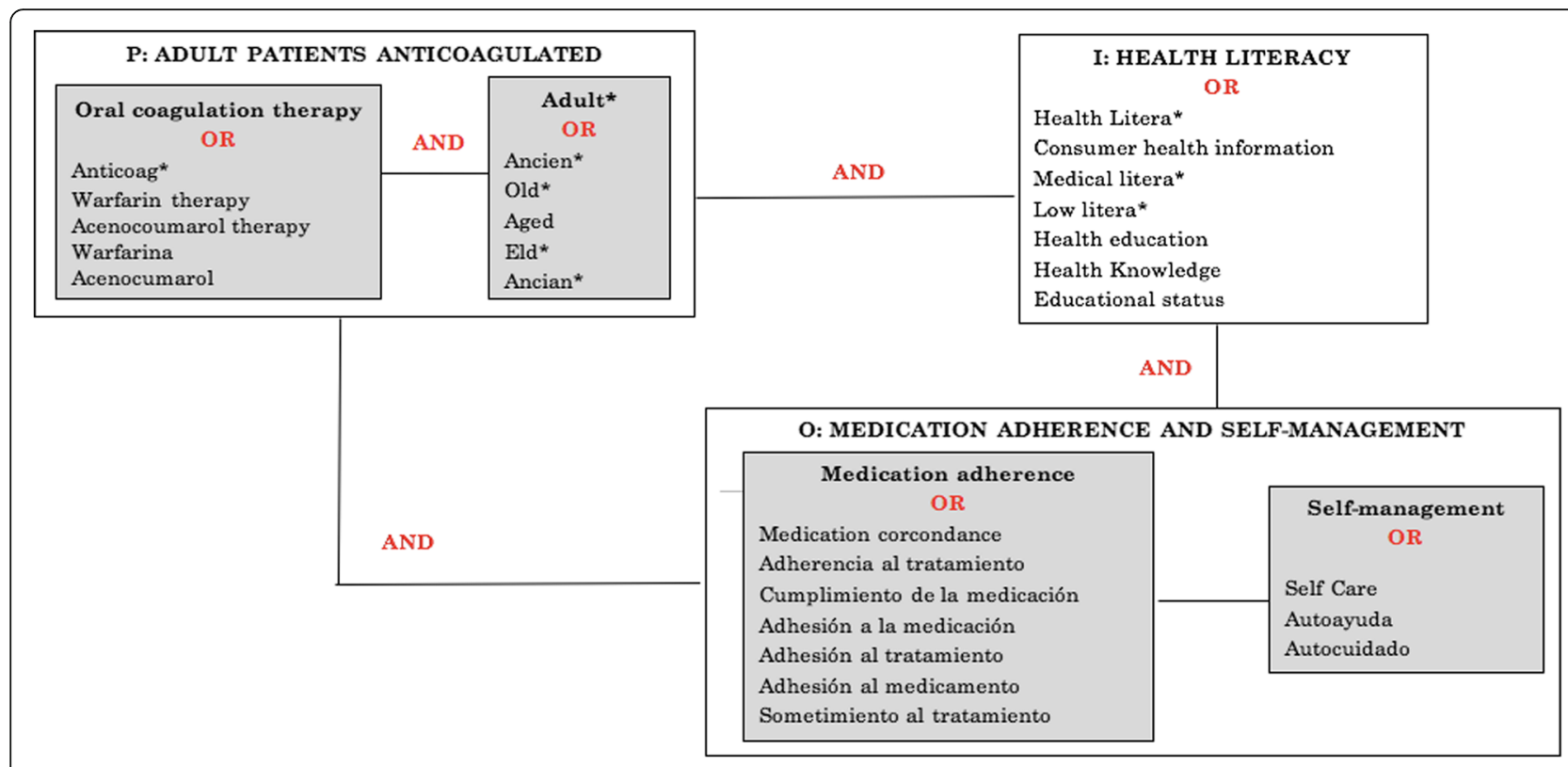

((( (health[ti] AND literacy[ti]) OR ("'health literacy"'" OR "'health literate"' OR "'"medical literacy'"') OR (functional[tw] AND health[tw] AND literacy[tw]) OR numeracy OR ((low literate[ti] OR low literacy[ti] $O R$ literacy[ti] $O R$ illiteracy[ti] $O R$ literate[ti] $O R$ illiterate[ti] OR reading[mh] OR comprehension[mh]) AND (health promotion[major] OR health education[major] OR patient education[major] OR Communication Barriers[major] OR communication[major:noexp] OR Health Knowledge, Attitudes, Practice[major] OR attitude to health[major])) OR (comprehension[major] AND educational status[major]) OR (family[ti] AND literacy[ti]) OR (("'"drug labeling"'" OR Prescriptions [mh]) AND ("'comprehension"'" OR "'"'numeracy"'")) OR ((cancer[ti] OR diabetes[ti]) AND (literacy[ti] OR comprehension[ti])) OR "''adult literacy"'" OR "'limited literacy"'" OR "'"patient understanding"'[ti] OR (self care [major] AND perception [mh]) OR (comprehension AND food labeling[mh]) OR (comprehension AND informed consent) OR (comprehension AND insurance, health)))) AND (((c((c(((((oral coagulation therapy) OR Warfarin Therapy) OR Acenocoumarol

Fig. 1 Systematic review search strategy and keywords

characteristics. In addition, we included information about the instrument used to assess $\mathrm{HL}, \mathrm{OAC}$ treatment, interventions/activities, risk of bias and results (Tables 2 and 3).

\section{Results}

\section{Search outcome and selection}

Figure 2 presents the study flow. Based on the electronic searches, we identified 142 original papers. Following removal of duplicates, 100 papers were title screened, 40 papers were abstract screened, and finally 10 papers were full-text screened.

\section{Methodological approaches of studies selected}

All 10 original papers selected were quantitative. The most frequently used study design was descriptive $(n=$ 7), including cross-sectional designs usually adjusted for age, sex and level of studies and with little inclusion of inferential methods. Three studies conducted longitudinal analyses, one of which was a randomized trial, [34] one cohort study [35] and one case-control study [36].

The variables collected in the studies were mainly sociodemographic, including the level of income in four articles [36-39]; others also collected data about medical history, including INR or TTR, although two articles did not have this marker $[39,40]$. Different tools were used to assess cognitive ability, including the Cognitive Abilities Screening Instrument-Short Form (S-CASI), Short Portable Mental Status Questionnaire (SPMSQ), Animal Naming Test (ANT) and the ABILHAND (to measure of manual ability for adults) [34, 39-43]. In terms of geographical location, nine studies were conducted in United States (US), [34, 35, 37-43] and one was originated from Australia [36]. No papers published in Europe were found. The most recent articles were published between 2014 and 2015 [37, 40].

\section{Methodological quality}

The 10 studies identified presented an acceptable methodological quality, following evaluation with the PRISMA guidelines and ICROMS tool to assess the Risk of Bias (Table 2). Selection and recall bias were the most commonly identified biases, present in two papers [34, 39] and [41, 43] respectively. One other paper presented social acceptability bias [43]. In addition, two articles included a rather small sample size $[38,42]$. 


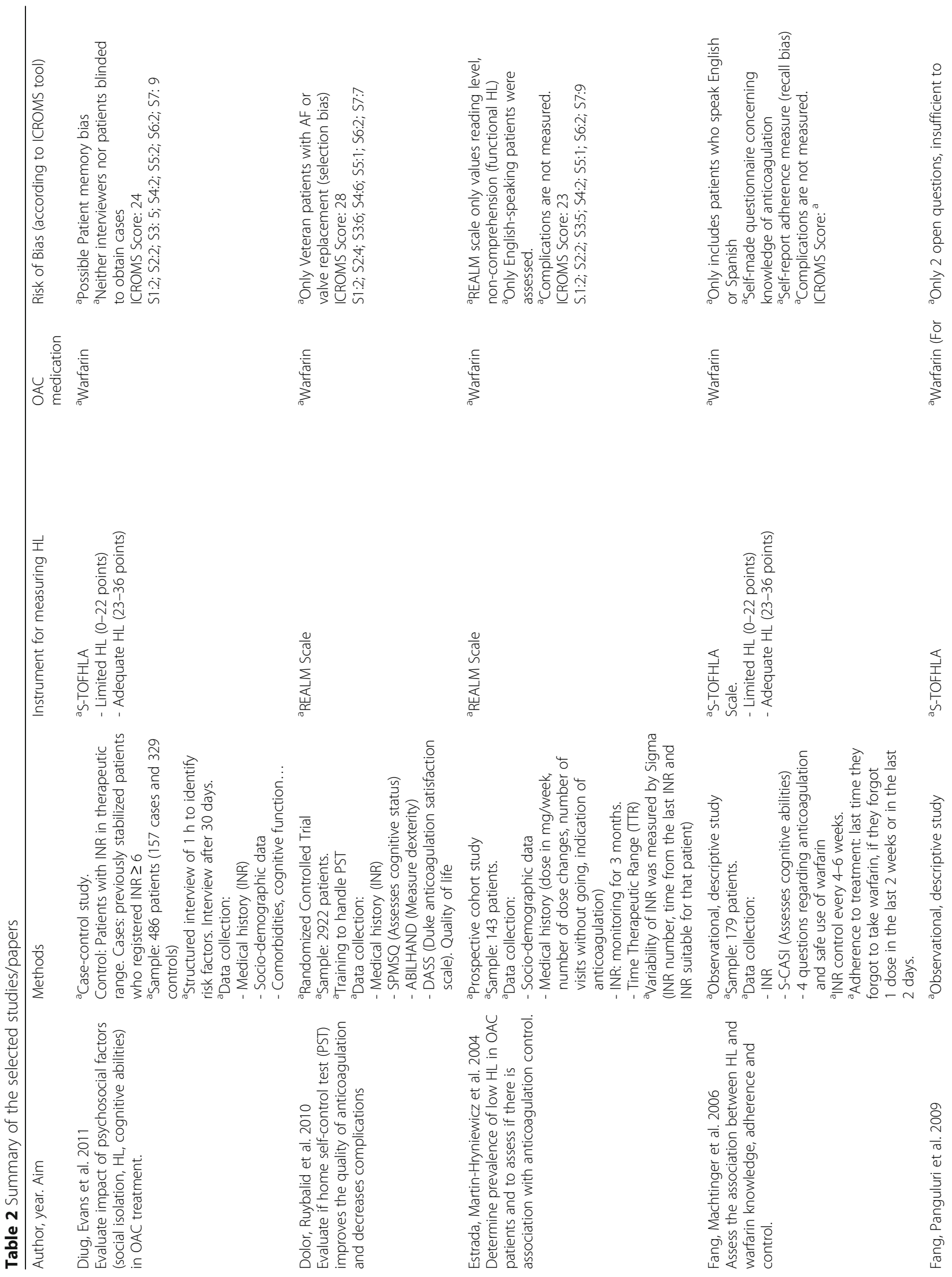




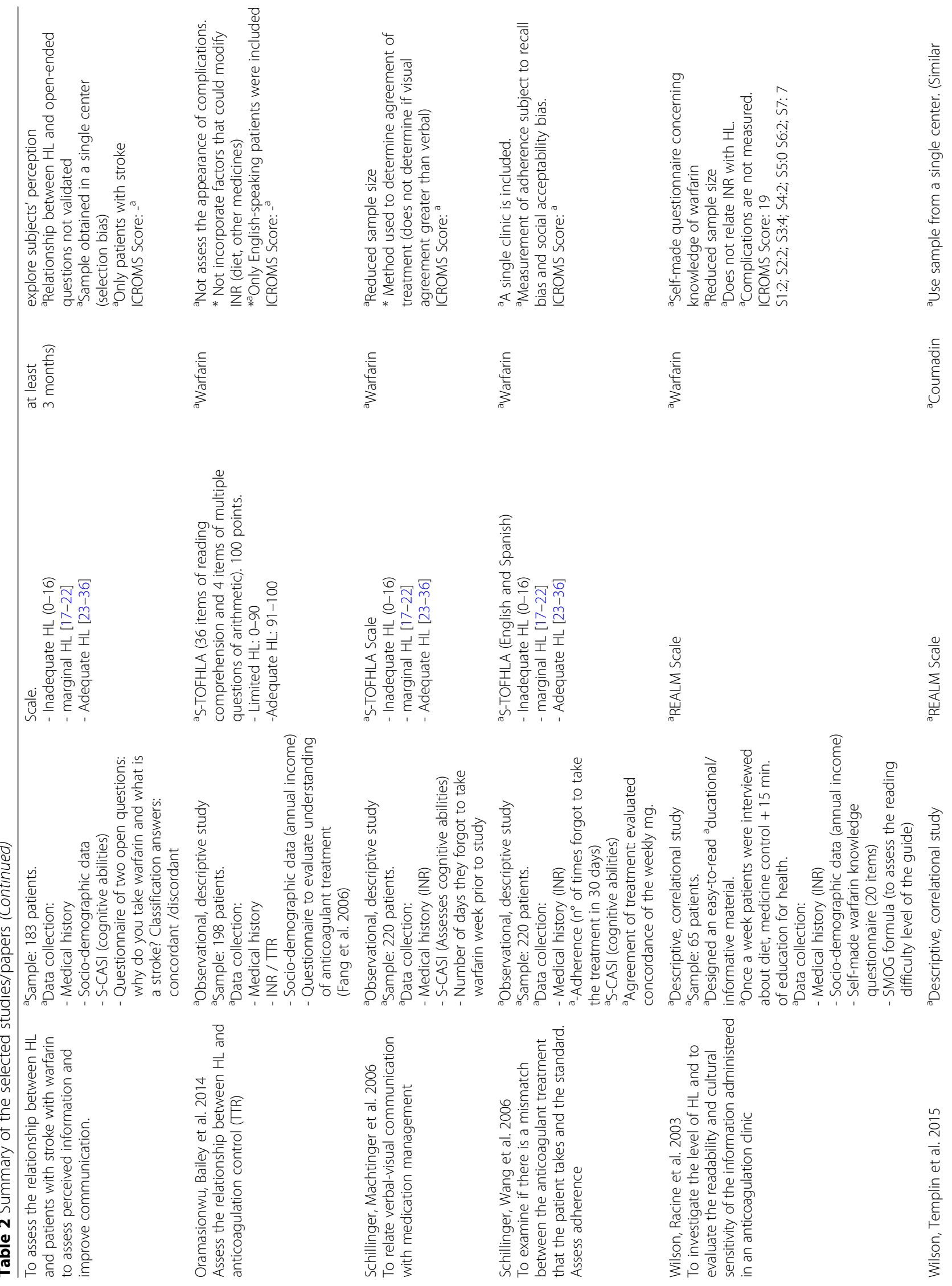




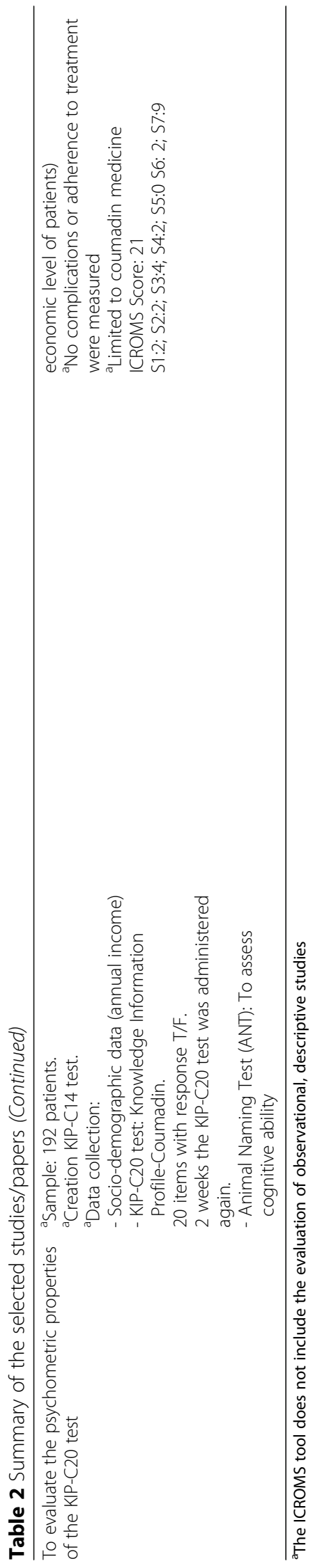




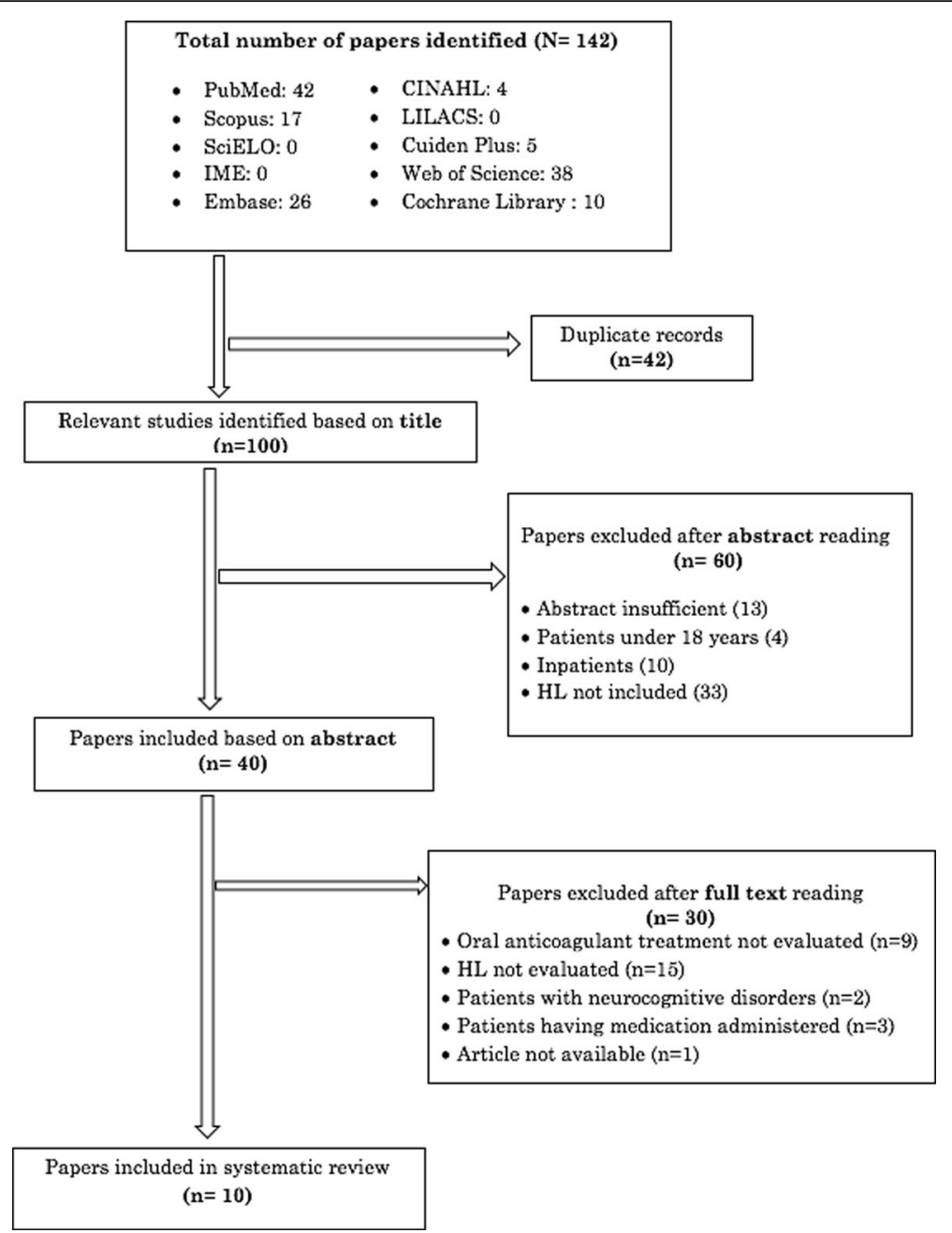

Fig. 2 Systematic review results chart

\section{Health literacy measurement tools}

All manuscripts included in the review used validated tools to measure HL. However, the tools were validated only in English-speaking or Spanish-speaking patients residing in the US. Of note, there were no tools validated in other Spanish-speaking populations. The most frequently validated tool used to measure HL was the short version of the Test of Functional Health Literacy in Adults (S-TOFHLA), present in six articles [36, 37, 39, 41-43] and the Rapid Estimate of Adult Literacy in Medicine (REALM) scale used in four articles [34, 35, 38, 40].

\section{Epidemiology of health literacy}

In seven studies about $50-60 \%$ of participants had limited or inadequate $\mathrm{HL},[36,37,39-43]$ studies used S-TOFHLA, whilst one employed the REALM tool. [40] Three studies (using REALM) obtained a prevalence of limited HL of $12-15 \%$ and adequate HL of around 70 $80 \%[34,35,38]$.
In terms of the relationship between $\mathrm{HL}$ and the age of the participants, five studies [35, 37-39, 41] reported an inverse relation between these variables. Further, women had lower HL levels in all except one study [38]. Regarding the association between HL and level of education, all studies demonstrated a direct relationship. One study qualified that participants with limited HL had lower levels of education, less employment, and lower annual income [37]. All selected studies directly related HL levels to educational or reading levels. In four studies the participants' annual income was included, $[36-38,40]$ but only one paper directly related it to the level of HL [37].

\section{Knowledge and sources of information}

Focusing on the health-related knowledge of participants and the different mechanisms used by them to obtain information, approximately 50\% of study participants received both written and verbal information from health 
Table 3 Main results of the selected studies/papers

\begin{tabular}{|c|c|}
\hline Author(s), year, country & Main results \\
\hline Diug, Evans et al. 2011, Australia & $\begin{array}{l}\text { - Inadequate } \mathrm{HL} \text {, cognitive impairment and depression were associated } \\
\text { with increased risk of bleeding (HL stronger relationship). } \\
\text { - Inadequate } \mathrm{HL} \text { in } 68 \% \text { cases and } 39 \% \text { controls. } \\
\text { - Group of cases worse adherence and less use of dispensers. }\end{array}$ \\
\hline Dolor, Ruybalid et al., 2010, USA & $\begin{array}{l}\text { - } 88.4 \% \text { successfully completed training } \\
\text { - Failure to perform PST NOT related to HL }\end{array}$ \\
\hline Estrada, Martin-Hryniewicz et al., 2004, USA & $\begin{array}{l}\text { - } 47.6 \% \text { have adequate } \mathrm{HL} \text { and } 11.2 \% \text { have inadequate } \mathrm{HL} \text {. } \\
\text { - Positive correlation between low } \mathrm{HL} \text { and greater variability in INR. } \\
\text { - HL level not associated with time remaining in range. }\end{array}$ \\
\hline Fang, Machtinger et al., 2006, USA & $\begin{array}{l}\text { - } 60.9 \% \text { have limited HL } \\
\text { - Median S-TOFHLA: } 17 \\
\text { - Limited HL was associated with knowledge deficit of its pathology (AF) } \\
\text { - Limited HL was not associated with INR in range or adherence. }\end{array}$ \\
\hline Fang, Panguluri et al., 2009, USA & $\begin{array}{l}\text { - S-CASI < } 17 \text { was associated with discordant responses in stroke and warfarin therapy } \\
\text { - Average score of S-TOFHLA:17 (marginal HL) } \\
\text { - Inadequate HL was associated with discordant responses }\end{array}$ \\
\hline Oramasionwu, Bailey et al., 2014, USA & $\begin{array}{l}\text { - Patients with limited HL have an older age, lower level of education, and lower } \\
\text { annual income. } \\
\text { - } 51 \% \text { have limited } \mathrm{HL} \text {. } \\
\text { - Limited } \mathrm{HL} \text { was associated with worse control }(\mathrm{TTR}<50 \%) \text { in adults> } 65 \text { years. }\end{array}$ \\
\hline Schillinger, Machtinger et al., 2006, USA & $\begin{array}{l}\text { - } 48 \% \text { inadequate } \mathrm{HL} \text { and } 13 \% \text { marginal } \mathrm{HL} \\
\text { - } 39 \% \text { adequate } \mathrm{HL} \\
\text {. } 56 \% \text { INR in range for } 90 \text { days } \\
\text { - Minor visual and verbal agreement in patients with insufficient } \mathrm{HL}\end{array}$ \\
\hline Schillinger, Wang et al., 2006, USA & $\begin{array}{l}.48 \% \text { inadequate } \mathrm{HL}, 13 \% \text { marginal } \mathrm{HL} \text { and } 39 \% \text { adequate } \mathrm{HL} \text {. } \\
.70 \% \text { maintained adherence but } 50 \% \text { presented discordant regimes } \\
.43 .8 \% \text { of INR was out of range. }\end{array}$ \\
\hline Wilson, Racine et al., 2003, USA & $\begin{array}{l}\text { - } 90 \% \text { knew that warfarin was anticoagulant, only } 50 \% \text { Knew side effects } \\
\text { - Significant relationship between } \mathrm{HL} \text { and knowledge level } \\
\text { - HL greater in women }\end{array}$ \\
\hline Wilson, Templin et al., 2015, USA & $\begin{array}{l}\text { - } 52.9 \% \text { score REALM between } 45 \text { and } 60 \text {. } \\
\text { - } 72.8 \% \text { responded correctly to the KIP-C20 } \\
\text { - Correlation between KIP-C14 and REALM was 9\%. } \\
\text { - Important gap in HL level. }\end{array}$ \\
\hline
\end{tabular}

professionals. The impact of such information however was less evident; one of the studies reported that $90 \%$ of patients knew which of their medicines was an oral anticoagulant, yet $70 \%$ were unaware of the need to monitor potential food interactions and a further $18 \%$ did not understand the side-effects [38]. Despite these gaps, $40 \%$ of participants felt their level of knowledge about treatment was good or moderate, which could lead to inequalities or discrepancies between their level of care and the interventions or recommendations implemented by healthcare professionals.

\section{Relationship between $\mathrm{HL}$ level, self-management of OAC and adverse effects}

Regarding the type of oral anticoagulant treatment reported, the most commonly used medication was warfarin (nine studies), [34-39, 41-43] with Coumadin used in one study [40].

\section{Relationship between HL level and self-management} When analysing the relationship between levels of HL and self-management of OAC treatments, the studies reported a relation between lower levels of HL, deficits of knowledge and increased risk of health problems such as bleeding and non-specific side effects or suboptimal treatment adherence. [35-37, 41, 42] Eight studies included INR measurements, with $30-50 \%$ of participants within adequate therapeutic range. [34-38, 41-43]; however, four studies $[34,38,42,43]$ did not link INR results to HL. Four studies [35-37, 41] established a relationship between the HL of participants and OAC treatment with contradictory results.

\section{Relationship between HL level and INR}

In the study by Fang et al. [41] with a sample of 179 patients in which INR control was performed every 46 weeks, a limited level of HL was not associated with INR within adequate range. The study by Oramasionwu 
et al. [37], on the other hand, with a sample of 198 adults older than 65 years but without clear information about the frequency of INR control suggested that limited HL was associated with poorer therapeutic control (TTR $<50 \%$ ). Finally, Estrada et al. [35] found that INR variability was $32 \%$ higher in patients at the lowest literacy level as compared with patients at the highest literacy level, but HL level not associated with time remaining in range, in a study of 143 patients where INR was monitored quarterly. In Australia, a case-control study reported that poor health literacy was the strongest relationship related to a higher INR and therefore higher bleeding risk. [36]

\section{Relationship between HL level, adherence and adverse effects}

With regards to adherence to the therapeutic regime, four studies evaluated this aspect obtaining disparate results. Two papers identified an association between HL and adherence to anticoagulant treatment, with lower HL linked to suboptimal adherence [36, 42].

Adverse effects and associated complications were examined by other two studies [36, 38]. In terms of participants' knowledge of possible complications or side effects, these studies were in agreement reporting a low percentage of participants who recognized adverse events and had difficulty adequately controlling INR. In the study by Wilson et al. [38], between 30 and $50 \%$ of participants were unaware of crucial side effects, whilst the study by Diug et al. [36] identified an association between inadequate levels of $\mathrm{HL}$ and increased risk of haemorrhage. This study also explored the impact of psychosocial factors and depression on self-management of OAC treatment. In the study, about $40 \%$ of participants had depression and it was associated with poorer control of treatment, poor adherence, inadequate HL, lower satisfaction and greater side effects, mainly increased risk of bleeding.

\section{Discussion}

Our review centred on the relation between HL, self-management and OAC treatment outcomes. We identified a limited number of studies on this topic, generally conducted in the US and focused on a rather small sample size (around 150 patients). There appeared to be large variability in the relationship between HL and different aspects of self-management of ACO treatment. The limited evidence available suggests a positive relationship between HL and the level of knowledge presented by patients on ACO treatment, in line with other pathologies where these aspects have been studied.

The results obtained in our review present some limitations, mainly due to the cross-sectional design of most studies in which HL measurement tools were used. As the description of results with respect to HL levels was often not detailed, comparison across studies may be inaccurate. In addition, HL was most frequently associated with knowledge only, yet the concept includes many other domains. Finally, the included studies lack generalizability to other settings and healthcare systems as most of them were conducted in the US.

HL was evaluated using mainly two validated tools (S-TOFHLA and REALM). A mix of tools were in place to examine different aspects about OAC treatment, including the Duke Anticoagulation Satisfaction Scale, [34] the questionnaire to evaluate understanding of anticoagulant treatment by Fang et al. [37], the KIP-C20 [40] and different other ad hoc questionnaires. In general, the methodologies and designs of the publications concur with previous studies evaluating HL in other health problems [44]. We therefore encourage the development and reporting of research where the relation and impact of factors such as self-care, treatment duration, disease stage, disease aetiology and HL level are considered. In addition, we highlight the lack of studies where interventions aimed at mitigating the impact of low HL on clinical and health outcomes are described $[45,46]$.

Despite the positive association between HL and the level of knowledge that all studies reflected, it is important to note that whilst different components and skills that inform or determine HL were evaluated in some of the studies discarded [47-51] HL was not specifically measured, which can make it difficult to make comparisons and lead to confusion. Paradigmatically, one of those studies [51] used two specific HL questions and assessed the readability of materials. However, it is increasingly acknowledged that HL is a much broader concept than readability and encompasses other social and critical elements [52]. As another difficulty, the different studies included a variety of HL strata, mostly using categories such as "inadequate", "marginal" or "adequate" but also "high" or "low", with several cut-off points stratifying HL levels. Additionally, the studies focused primarily on the differences between groups with higher or lower HL, rather than elaborating on the differences between the different groups.

Additionally, there seems to be a growing interest in developing validated, pathology-specific, HL measurement instruments, as seen for example in diabetes, rheumatism, colon cancer, hypertension, and Human Immunodeficiency Virus (HIV) [52]. Whether such efforts are warranted would demand theoretical underpinnings demonstrating that HL skills associated with those health problems or others are different to the domains included in general HL screening tools. For the moment, and focusing on OAC treatments, there is no validated tool for the evaluation of health literacy in cardiac pathologies such as AF. 
The review reveals a widespread absence of evaluation between HL and subsequent complications or increased hospital admissions. When such association was included, it was found to be weak. Such findings mirror the conclusions of a systematic review assessing the relationship between HL and diabetes outcomes, [53] with limited evidence linking HL and serious clinical events. In contrast, another systematic review [52] postulated that low HL levels were associated with increased use of health services, including hospitalizations and use of emergency facilities.

Our review identified some inconsistencies between HL levels and adherence to treatment. In the four studies that quantified such association, only two demonstrated a positive association. Some factors that could explain such disparity may include the different adherence assessment methods used, including self-reported tools which may lead to recall bias. Regarding INR control, the two studies measuring this relationship diverged in their conclusions, with one experience linking limited HL to worse TTR control [37] and another not identifying any association between health literacy and TTR. [54] Finally, a slightly different approach was reported by Tang et al. [55] who positively correlated the level of patient knowledge and the frequency of INR measurements within the appropriate range. Interestingly, studies in other clinical areas have arrived at similar range of results. For example, whilst HL was associated with better adherence to glaucoma treatment [56] and glycaemic control, [57] this was not the case in experiences focused on HIV therapy or oral contraception [58].

\section{Conclusion}

Even considering the narrow scientific evidence and the limitations of the studies found, it seems appropriate to suggest that improving HL levels among patients taking OAC treatment would lead to increased self-management and therefore facilitate optimal use of health services. To achieve such goal, healthcare organisations should evaluate their resources and clinical pathways to ensure that patients with low HL can be supported and any associated inequalities in outcomes are addressed. In parallel, it may also be essential to tackle the impact of main determinants of HL such as education and socioeconomic status to ensure that patients are able to mitigate risk factors contributing to pathologies which require OAC treatments.

\section{Additional file}

Additional file 1: PRISMA checklist. (DOC $63 \mathrm{~kb}$ )

\section{Abbreviations}

AF: Atrial fibrillation; ANT: Animal naming test; DASS: Duke anticoagulation satisfaction scale; DeCS: Descriptores en Ciencias de la Salud; ESC: European
Society of Cardiology; HIV: Human immunodeficiency Virus; HL: Health literacy; ICROMS: Integrated quality Criteria for the Review of Multiple Study designs; INR: International normalized Ratio; KIP-C20: Knowledge Information Profile-Coumadin; MeSH: Medical subject Headings; OAC: Oral anticoagulation; PRISMA: Preferred reporting Items for Systematic Reviews and Meta-Analyses; PST: Patient self-testing; REALM: Rapid estimate of Adult Literacy in Medicine; SCASI: Cognitive abilities Screening Instrument-Short Form; SMOG: Simple measure of Gobbledygook; SPMSQ: Short portable Mental Status Questionnaire; S-TOFHLA: Test of Functional Health Literacy in Adults; TTR: Time in therapeutic Range; US: United States; WHO: World Health Organization

\section{Funding}

This research received no specific grant from any funding agency in the public, commercial, or not-for-profit sectors. ECS is affiliated with the National Institute for Health Research (NIHR) Health Protection Research Unit (HPRU) in Healthcare Associated Infection and Antimicrobial Resistance at Imperial College London in partnership with Public Health England (PHE), and the NIHR Imperial Patient Safety Translational Research Centre. ECS has received a Wellcome ISSF Faculty Fellowship and an ARC Fellowship at Imperial College London, and acknowledges the support of the Florence Nightingale Foundation. The views expressed are those of the authors and not necessarily those of the NHS, the NIHR, the Department of Health, or Public Health England.

\section{Availability of data and materials}

All data generated or analysed during this study are included in this published article [and its Additional file 1].

\section{Authors' contributions}

ECS, VGC and ACG conceived the Study. ECS VGC, ACG and AMS prepared the Study protocol, planned and revised the research Strategy. ACG and RJV carried out the literature search and primary analysis. AMS, VGC and MK validated the primary analysis. All authors agreed on the article selection. ECS, VGC, ACG, AMS wrote the first draft. RJV and MK reviewed the final good draft. All authors are responsible for the research reported, and have seen and approved the manuscript as submitted. All authors have contributed significantly to the work.

\section{Ethics approval and consent to participate}

Not applicable.

Consent for publication

Not applicable.

\section{Competing interests}

ECS is an editorial board member for BMC Public Health since March 2018. The authors declare that they have no competing interests.

\section{Publisher's Note}

Springer Nature remains neutral with regard to jurisdictional claims in published maps and institutional affiliations.

\section{Author details}

${ }^{1}$ Unidad de cuidados intensivos, Hospital Universitario y politécnico La Fe, Valencia, Spain. ${ }^{2}$ Nursing Department, University of Valencia, Valencia, Spain. ${ }^{3} \mathrm{NIHR}$ Health Protection Research Unit in Healthcare Associated Infection and Antimicrobial Resistance at Imperial College London, Du Cane Road, W12 0NN, London, UK. ${ }^{4}$ Department of Nursing Science, Faculty of Health Sciences, University of Eastern Finland, Kuopio, Finland. ${ }^{5}$ Universidad San Jorge de Zaragoza, Villanueva de Gállego, Zaragoza, Spain. ${ }^{6}$ Escuela de Enfermería La Fe, centro adscrito Universidad de Valencia, Valencia, Spain. ${ }^{7}$ Instituto de Investigación La Fe. Grupo de investigación GREIACC, Valencia, Spain.

Received: 24 January 2018 Accepted: 25 September 2018

Published online: 04 October 2018

\section{References}

1. January CT, Wann LS, Alpert JS, Calkins H, Cigarroa JE, Cleveland JC, et al. 2014 AHA/ACC/HRS guideline for the management of patients with atrial fibrillation: a report of the American College of Cardiology/American Heart 
Association task force on practice guidelines and the Heart Rhythm Society. J Am Coll Cardiol. 2014;64(21):1.

2. Camm AJ, Lip GYH, De Caterina R, Savelieva I, Atar D, Hohnloser SH, et al. 2012 focused update of the ESC guidelines for the management of atrial fibrillation: an update of the 2010 ESC guidelines for the management of atrial fibrillation--developed with the special contribution of the European heart rhythm association. Europace. 2012;14(10):1385-413.

3. Boned-Ombuena A, Pérez-Panadés J, López-Maside A, Miralles-Espí M, Guardiola Vilarroig S, Adam Ruiz D, et al. Prevalencia de la anticoagulación oral y calidad de su seguimiento en el ámbito de la atención primaria: estudio de la Red Centinela Sanitaria de la Comunitat Valenciana. Aten Primaria. 2017:49(9):534-48.

4. Gómez-Doblas JJ, Muñiz J, Martin JJA, Rodríguez-Roca G, Lobos JM, Awamleh P, et al. Prevalencia de fibrilación auricular en España. Resultados del estudio OFRECE. Rev Esp Cardiol. 2014;67(04):259-69.

5. Esmerio FG, Souza EN, Leiria TL, Lunelli R, Moraes MA. Uso crónico de anticoagulante oral: implicaciones para el control de niveles adecuados. Arq Bras Cardiol. 2009;93(5):549-54.

6. Navarro JL, Cesar JM, Fernández MA, Fontcuberta J, Reverter JC, Gol-Freixa J. Morbilidad y mortalidad en pacientes con tratamiento anticoagulante oral. Rev Esp Cardiol. 2007;60(12):1226-32.

7. Kirchhof P, Benussi S, Kotecha D, Ahlsson A, Atar D, Casadei B, et al. 2016 ESC Guidelines for the management of atrial fibrillation developed in collaboration with EACTS. Eur Heart J. 2016;37(38):2893-962.

8. Steffel J, Verhamme P, Potpara TS, Albaladejo P, Antz M, Desteghe L, et al. The 2018 European heart rhythm association practical guide on the use of non-vitamin $\mathrm{K}$ antagonist oral anticoagulants in patients with atrial fibrillation: executive summary. EP Europace. 2018;20(8):1231-42. https://doi. org/10.1093/europace/euy054.

9. Matsuoka S, Tsuchihashi-Makaya M, Kayane T, Yamada M, Wakabayashi R, Kato $N P$, et al. Health literacy is independently associated with self-care behavior in patients with heart failure. Patient Educ Couns. 2016;99(6):1026-32.

10. Chen AMH, Yehle KS, Plake KS, Murawski MM, Mason HL. Health literacy and self-care of patients with heart failure. J Cardiovasc Nurs. 2011;26(6):446-51.

11. Sorensen K, Van den Broucke S, Fullam J, Doyle G, Pelikan J, Slonska Z, et al. Health literacy and public health: a systematic review and integration of definitions and models. BMC Public Health. 2012;12:80.

12. Peerson A, Saunders M. Health literacy revisited: what do we mean and why does it matter? Health Promot Int. 2009;24(3):285-96.

13. Berkman ND, Davis TC, McCormack L. Health literacy: what is it? J Health Commun. 2010;15(Suppl 2):9-19.

14. Altin SV, Finke I, Kautz-Freimuth S, Stock S. The evolution of health literacy assessment tools: a systematic review. BMC Public Health. 2014;14:1207.

15. Jordan JE, Osborne RH, Buchbinder R. Critical appraisal of health literacy indices revealed variable underlying constructs, narrow content and psychometric weaknesses. J Clin Epidemiol. 2011;64(4):366-79.

16. McCormack L, Bann C, Squiers L, Berkman ND, Squire C, Schillinger D, et al. Measuring health literacy: a pilot study of a new skills-based instrument. J Health Commun. 2010;15(Suppl 2):51-71.

17. Reading SR, Go AS, Fang MC, Singer DE, Liu IA, Black MH, et al. Health literacy and awareness of atrial fibrillation. J Am Heart Assoc. 2017;6(4):1-11.

18. Davis TC, Wolf MS. Health literacy: implications for family medicine. Fam Med. 2004:36(8):595-8.

19. Parker RM, Ratzan SC, Lurie N. Health literacy: a policy challenge for advancing high-quality health care. Health Aff (Millwood). 2003;22(4):147-53.

20. Davis TC, Wolf MS, Bass PF, Middlebrooks M, Kennen E, Baker DW, et al. Low literacy impairs comprehension of prescription drug warning labels. J Gen Intern Med. 2006;21(8):847-51.

21. Baker DW, Gazmararian JA, Williams MV, Scott T, Parker RM, Green D, et al. Functional health literacy and the risk of hospital admission among Medicare managed care enrollees. Am J Public Health. 2002;92(8):1278-83.

22. Sudore RL, Yaffe K, Satterfield S, Harris TB, Mehta KM, Simonsick EM, et al. Limited literacy and mortality in the elderly: the health, aging, and body composition study. J Gen Intern Med. 2006;21(8):806-12.

23. Howard DH, Sentell T, Gazmararian JA. Impact of health literacy on socioeconomic and racial differences in health in an elderly population. J Gen Intern Med. 2006;21(8):857-61.

24. Bostock S, Steptoe A. Association between low functional health literacy and mortality in older adults: longitudinal cohort study. BMJ. 2012;344:e1602.

25. DeWalt DA, Berkman ND, Sheridan S, Lohr KN, Pignone MP. Literacy and health outcomes. J Gen Intern Med. 2004;19(12):1228-39.
26. Parker R. Health literacy: a challenge for American patients and their health care providers. Health Promot Int. 2000;15(4):277-83.

27. Baker DW, Wolf MS, Feinglass J, Thompson JA, Gazmararian JA, Huang J. Health literacy and mortality among elderly persons. Arch Intern Med. 2007; 167(14):1503-9.

28. Gazmararian JA, Williams MV, Peel J, Baker DW. Health literacy and knowledge of chronic disease. Patient Educ Couns. 2003;51(3):267-75.

29. Scott TL, Gazmararian JA, Williams MV, Baker DW. Health literacy and preventive health care use among Medicare enrollees in a managed care organization. Med Care. 2002;40(5):395-404.

30. Moher D, Liberati A, Tetzlaff J, Altman DG. Preferred reporting items for systematic reviews and meta-analyses: the PRISMA statement. Int I Surg. 2010;8(5):336-41.

31. Zingg W, Castro-Sanchez E, Secci FV, Edwards R, Drumright LN, Sevdalis N, et al. Innovative tools for quality assessment: integrated quality criteria for review of multiple study designs (ICROMS). Public Health. 2016;133:19-37.

32. Mueller M, D'Addario M, Egger M, Cevallos M, Dekkers O, Mugglin C, et al. Methods to systematically review and meta-analyse observational studies: a systematic scoping review of recommendations. BMC Med Res Methodol. 2018;18(1):44

33. Storr J, Twyman A, Zingg W, Damani N, Kilpatrick C, Reilly J, et al. Core components for effective infection prevention and control programmes: new WHO evidence-based recommendations. Antimicrob Resist Infect Control. 2017;6:6.

34. Dolor RJ, Ruybalid RL, Uyeda L, Edson RG, Phibbs C, Vertrees JE, et al. An evaluation of patient self-testing competency of prothrombin time for managing anticoagulation: pre-randomization results of VA cooperative study \#481--the home INR study (THINRS). J Thromb Thrombolysis. 2010; 30(3):263-75.

35. Estrada CA, Martin-Hryniewicz M, Peek BT, Collins C, Byrd JC. Literacy and numeracy skills and anticoagulation control. Am J Med Sci. 2004; 328(2):88-93.

36. Diug B, Evans S, Lowthian J, Maxwell E, Dooley M, Street A, et al. The unrecognized psychosocial factors contributing to bleeding risk in warfarin therapy. Stroke. 2011;42(10):2866-71.

37. Oramasionwu CU, Bailey SC, Duffey KE, Shilliday BB, Brown LC, Denslow SA, et al. The association of health literacy with time in therapeutic range for patients on warfarin therapy. J Health Commun. 2014;19(Suppl 2):19-28.

38. Wilson FL, Racine E, Tekieli V, Williams B. Literacy, readability and cultural barriers: critical factors to consider when educating older African Americans about anticoagulation therapy. J Clin Nurs. 2003;12(2):275-82.

39. Fang MC, Panguluri P, Machtinger EL, Schillinger D. Language, literacy, and characterization of stroke among patients taking warfarin for stroke prevention: implications for health communication. Patient Educ Couns. 2009;75(3):403-10.

40. Wilson FL, Templin TN, Nordstrom CK, Carter JM, Baker L, Kinney T, et al, Psychometric properties and construct validity of the knowledge information profile-Coumadin. J Pharm Technol. 2015;31(1):20-8.

41. Fang MC, Machtinger EL, Wang F, Schillinger D. Health literacy and anticoagulation-related outcomes among patients taking warfarin. J Gen Intern Med. 2006;21(8):841-6.

42. Schillinger D, Machtinger EL, Wang F, Palacios J, Rodriguez M, Bindman A. Language, literacy, and communication regarding medication in an anticoagulation clinic: a comparison of verbal vs. visual assessment. J Health Commun. 2006;11(7):651-64.

43. Schillinger D, Wang F, Rodriguez M, Bindman A, Machtinger EL. The importance of establishing regimen concordance in preventing medication errors in anticoagulant care. J Health Commun. 2006;11(6):555-67.

44. Al Sayah F, Majumdar SR, Williams B, Robertson S, Johnson JA. Health literacy and health outcomes in diabetes: a systematic review. J Gen Intern Med. 2013;28(3):444-52.

45. Aronis KN, Edgar B, Lin W, Martins MAP, Paasche-Orlow MK, Magnani JW. Health literacy and atrial fibrillation: relevance and future directions for patient-centred care. Eur Cardiol. 2017;12(1):52-7.

46. Hassali MA, Lim CJ, Rajah R. Health literacy-related knowledge, attitude, and perceived barriers: a cross-sectional study among physicians, pharmacists, and nurses in public hospitals of Penang, Malaysia. Front Public Health. 2017;5:281.

47. Alphonsa A, Sharma KK, Sharma G, Bhatia R. Knowledge regarding oral anticoagulation therapy among patients with stroke and those at high risk of thromboembolic events. J Stroke Cerebrovasc Dis. 2015;24(3):668-72. 
48. Chenot J, Hua TD, Abu Abed M, Schneider-Rudt H, Friede T, Schneider S, et al. Safety relevant knowledge of orally anticoagulated patients without selfmonitoring: a baseline survey in primary care. BMC Fam Pract. 2014;15:104-12.

49. Mavri A, Ostasevski Fernandez N, Kramaric A, Kosmelj K. New educational approach for patients on warfarin improves knowledge and therapy control. Wien Klin Wochenschr. 2015;127(11-12):472-6.

50. Michal M, Prochaska JH, Ullmann A, Keller K, Gobel S, Coldewey M, et al. Relevance of depression for anticoagulation management in a routine medical care setting: results from the ThrombEVAL study program. J Thromb Haemost. 2014;12(12):2024-33.

51. Schwartz L, Mazzola N, Hoffman RS, Howland MA, Mercurio-Zappala M, Nelson LS. Evaluating Patients' understanding of printed warfarin medication information. J Pharm Pract. 2015;28(6):518-22.

52. Bas Sarmiento P, Fernández Gutiérrez M, Poza Méndez M, Pelicano PN. Propuestas de evaluación de la Alfabetización en Salud. Psychologia Latina. 2015;6(1):1-11.

53. Berkman ND, Sheridan SL, Donahue KE, Halpern DJ, Crotty K. Low health literacy and health outcomes: an updated systematic review. Ann Intern Med. 2011;155(2):97-107.

54. Martins MAP, Costa JM, Mambrini JV d M, Ribeiro ALP, Benjamin EJ, Brant LCC, et al. Health literacy and warfarin therapy at two anticoagulation clinics in Brazil. Heart. 2017;103(14):1089-95.

55. Tang EOYL, Lai CSM, Lee KKC, Wong RSM, Cheng G, Chan TYK. Relationship between patients' warfarin knowledge and anticoagulation control. Ann Pharmacother. 2003;37(1):34-9.

56. Keller DL, Wright J, Pace HA. Impact of health literacy on health outcomes in ambulatory care patients: a systematic review. Ann Pharmacother. 2008; 42(9):1272-81.

57. Schillinger D, Grumbach K, Piette J, Wang F, Osmond D, Daher C, et al. Association of health literacy with diabetes outcomes. JAMA. 2002;288(4): 475-82.

58. Muir KW, Santiago-Turla C, Stinnett SS, Herndon LW, Allingham RR, Challa P, et al. Health literacy and adherence to glaucoma therapy. Am J Ophthalmol. 2006;142(2):223-6.

Ready to submit your research? Choose BMC and benefit from:

- fast, convenient online submission

- thorough peer review by experienced researchers in your field

- rapid publication on acceptance

- support for research data, including large and complex data types

- gold Open Access which fosters wider collaboration and increased citations

- maximum visibility for your research: over $100 \mathrm{M}$ website views per year

At $\mathrm{BMC}$, research is always in progress.

Learn more biomedcentral.com/submissions 